\title{
Gallic acid induces HeLa cell death via increasing GSH depletion rather than ROS levels
}

\author{
WOO HYUN PARK

\begin{abstract}
Department of Physiology, Medical School, Research Institute for Endocrine Sciences,
\end{abstract} \\ Chonbuk National University, JeonJu 561-180, Republic of Korea
}

Received August 3, 2016; Accepted December 19, 2016

DOI: $10.3892 /$ or.2016.5335

\begin{abstract}
Gallic acid (GA; 3,4,5-triphydroxyl-benzoic acid) is widely dispersed in various plants, fruits and foods and it shows various biological properties including anticancer effects. This study investigated the effects of GA on HeLa cervical cancer cells in relation to cell death, reactive oxygen species (ROS) and glutathione (GSH). GA dose-dependently inhibited the growth of HeLa cells and human umbilical vein endothelial cells (HUVEC) at 24 or $72 \mathrm{~h}$. The susceptibility of HeLa cells to GA was higher than that of HUVEC. GA induced apoptosis in HeLa cells, which was accompanied by the loss of mitochondrial membrane potential (MMP; $\Delta \Psi_{\mathrm{m}}$ ). GA increased ROS levels including $\mathrm{O}_{2}{ }^{-}$in HeLa cells at $24 \mathrm{~h}$ and it also induced GSH depletion. N-acetyl cysteine (NAC) increased the growth inhibition of GA-treated HeLa cells and enhanced the death of these cells. NAC differently influenced ROS levels in GA-treated HeLa cells and significantly increased GSH depletion in these cells. L-buthionine sulfoximine (BSO) increased MMP $\left(\Delta \Psi_{\mathrm{m}}\right)$ loss, ROS levels and GSH depletion in GA-treated HeLa cells. In conclusion, GA significantly inhibited the growth of HeLa cells. GA-induced HeLa cell death was tightly related to GSH depletion rather than ROS level changes.
\end{abstract}

Correspondence to: Professor Woo Hyun Park, Department of Physiology, Medical School, Research Institute for Endocrine Sciences, Chonbuk National University, JeonJu 561-180, Republic of Korea

E-mail: parkwh71@jbnu.ac.kr

Abbreviations: GA, gallic acid, HUVEC; human umbilical vein endothelial cells; ROS, reactive oxygen species; MMP $(\Delta \Psi \mathrm{m})$, mitochondrial membrane potential; MTT, 3-(4,5-dimethylthiazol-2-yl)2,5-diphenyltetrazolium bromide; $\mathrm{H}_{2}$ DCFDA, 2',7'-dichlorodihydrofluorescein diacetate; DHE, dihydroethidium; GSH, glutathione; CMFDA, 5-chloromethylfluorescein diacetate; NAC, N-acetyl cysteine; BSO, L-buthionine sulfoximine

Key words: gallic acid, cell death, HeLa, reactive oxygen species, glutathione

\section{Introduction}

Gallic acid (GA; 3,4,5-triphydroxyl-benzoic acid) and its derivatives are broadly distributed in a variety of plants, fruits and foods. Especially, walnuts, green tea, grapes, strawberries, bananas, lemons, pineapples, wines and apple peels are recognized to be high in GA (1). GA is being used as food additives, and preservatives. GA is very well absorbed in humans; free and glucuronidated forms of GA and its main metabolite 4-O-methylgallic have been observed to a large extent in human blood plasma after intake of foods containing plenty of GA (2).

GA possesses various biological or pharmacological activities including anti-bacterial (3), anti-viral (4) and antiinflammatory effects (5). The major attention given to GA is due to its antitumoral or anticancer effect. For example, GA inhibits the growth of various cancer cells such as lung cancer (6,7), leukemia (8), prostate cancer (9), gastric, colon, breast, cervical and esophageal cancers $(10,11)$. GA can trigger apoptosis via stimulating oxidative stress and/or increasing intracellular $\mathrm{Ca}^{2+}$ levels $(6-8,12)$. However, GA shows somewhat lesser cytotoxicity against normal endothelial and fibroblast cells (13). In addition, GA reveals an anti-apoptotic potential in normal human lymphocytes (14). GA has been considered as a useful phytochemical for cancer chemoprevention (15). Interestingly, GA can be a pro-oxidant or an antioxidant depending on iron or $\mathrm{H}_{2} \mathrm{O}_{2}$ in medium and plasma $(16,17)$. Therefore, further studies need to be performed to re-evaluate its biological functions and roles under the different situations.

Reactive oxygen species (ROS) such as superoxide anion $\left(\mathrm{O}_{2}{ }^{-}\right)$, hydroxyl radical $\left({ }^{\circ} \mathrm{OH}\right)$ and hydrogen peroxide $\left(\mathrm{H}_{2} \mathrm{O}_{2}\right)$ are involved in many important cellular functions of cell proliferation, differentiation and apoptosis $(18,19)$. Alteration in the redox status of tissues and cells influences the production or metabolism of ROS. They are generated as by-products of mitochondrial respiration or certain oxidases such as nicotinamide adenine dinucleotide phosphate oxidase and xanthine oxidase (20). The primary metabolic antioxidant enzyme is superoxide dismutase (SOD), which metabolize $\mathrm{O}_{2}{ }^{-}$ to $\mathrm{H}_{2} \mathrm{O}_{2}(21)$. Further metabolism by other antioxidant enzymes such as catalase and glutathione (GSH) peroxidase, yields $\mathrm{O}_{2}$ and $\mathrm{H}_{2} \mathrm{O}$ (22). Cells possess various antioxidant systems to control the redox state, which is important for their survival. Oxidative stress may be the result of either overproduction of 
ROS or accumulation of it due to the failure of antioxidant systems, consequently inducing cell dysfunction or cell death.

Cervical cancer is a foremost cause of cancer-related death in women worldwide. The carcinogenesis is considered to be connected with excessive inflammation mediated by ROS. It was previously demonstrated that GA induces the growth inhibition and death in GA-treated HeLa cervical cancer cells (11). However, the underlying mechanism remains unclear in view of redox state changes in GA-treated HeLa cells. Thus, this study assessed the effects of GA on ROS and GSH levels in HeLa cells and investigated the cellular effects of $\mathrm{N}$-acetyl cysteine (NAC; a well known antioxidant) and buthionine sulfoximine (BSO; an inhibitor of GSH synthesis) on GA-treated HeLa cells in relation to cell death.

\section{Materials and methods}

Cell culture. The human cervix adenocarcinoma HeLa cells obtained from the American Type Culture Collection (ATCC, Manassas, VA, USA) were cultured in RPMI-1640 supplemented with $10 \%$ fetal bovine serum (Sigma-Aldrich Chemical Co., St. Louis, MO, USA) and $1 \%$ penicillin-streptomycin (Gibco BRL, Grand Island, NY, USA). The primary human umbilical vein endothelial cells (HUVEC) purchased from PromoCell GmbH (Heidelberg, Germany) were cultured in complete endothelial cell growth medium (ECGM, Promocell) with $2 \%$ FBS. HUVEC were washed and detached with HEPES-BSS (30 mM HEPES), trypsin-EDTA and trypsin neutralization solution (Promocell). The HUVEC between passages four and eight were utilized for the experiments.

Reagents. GA was purchased from the Sigma-Aldrich Chemical Co. and was dissolved in $100 \%$ ethanol at $200 \mathrm{mM}$. NAC and BSO were also obtained from Sigma-Aldrich Chemical Co. NAC and BSO were obtained from Sigma-Aldrich Chemical Co. NAC was dissolved in the buffer $[20 \mathrm{mM}$ HEPES ( $\mathrm{pH}$ 7.0)]. BSO was dissolved in water. Based on a previous study (23), exponentially growing cells were treated with the indicated amounts of GA for 24 or $72 \mathrm{~h}$ following one hour pre-incubation of $2 \mathrm{mM}$ NAC or $10 \mu \mathrm{M}$ BSO.

Growth inhibition assay. Changes in cell growth were assessed by measuring the 3-(4,5-dimethylthiazol-2-yl)-2,5-diphenyltetrazolium bromide (MTT, Sigma-Aldrich Chemical Co.) dye absorbance as previously described (24). Cells were exposed to the indicated amounts of GA with or without NAC or BSO for 24 or $72 \mathrm{~h}$.

Detection of intracellular ROS levels. Intracellular ROS were assessed by a fluorescent probe dye, 2',7'-dichlorodihydrofluorescein diacetate $\left(\mathrm{H}_{2} \mathrm{DCFDA}\right.$; Invitrogen Molecular Probes, Eugene, OR, USA). Dihydroethidium (DHE, Invitrogen Molecular Probes) is a fluorogenic probe which is highly selective for $\mathrm{O}_{2}{ }^{--}$among ROS. Cells were incubated with the indicated amounts of GA with or without NAC or BSO for 0.5 , 1, 2, 24 or 72 h. Cells were then washed in PBS and incubated with $20 \mu \mathrm{M} \mathrm{H}_{2} \mathrm{DCFDA}$ or DHE at $37^{\circ} \mathrm{C}$ for $30 \mathrm{~min}$. DCF and DHE fluorescences were detected using a FACStar flow cytometer (Becton-Dickinson, Franklin Lakes, NJ, USA). ROS levels were expressed as mean fluorescence intensity (MFI).
Detection of the intracellular glutathione (GSH). Cellular GSH levels were analyzed using a 5-chloromethylfluorescein diacetate dye (CMFDA, Invitrogen Molecular Probes) as previously described (25). Cells were incubated with the indicated amounts of GA with or without NAC or BSO for 0.5, 1, 2, 24 or $72 \mathrm{~h}$. CMF fluorescence intensity was determined using a FACStar flow cytometer (Becton-Dickinson). Negative CMF staining (GSH depleted) cells were expressed as the percent of (-) CMF cells. CMF levels in cells except (-) CMF cells were expressed as MFI, which was calculated by CellQuest software (Becton-Dickinson).

Annexin $V$ staining for apoptosis detection. Apoptosis was analyzed by staining cells with Annexin V-fluorescein isothiocyanate (FITC; Invitrogen Molecular Probes) as previously described (26). Cells were incubated with the indicated amounts of GA with or without NAC or BSO for $24 \mathrm{~h}$. Annexin V-FITC staining cells were analyzed with a FACStar flow cytometer (Becton-Dickinson).

Measurement of mitochondrial membrane potential $\left(M M P ; \Delta \Psi_{m}\right)$. MMP $\left(\Delta \Psi_{\mathrm{m}}\right)$ levels were measured using a Rhodamine 123 fluorescent dye (Sigma-Aldrich Chemical Co.; Ex/Em = 485/535 nm) as previously described (27). Cells were incubated with the indicated amounts of GA with or without NAC or BSO for $24 \mathrm{~h}$. Rhodamine 123 staining intensity was determined by flow cytometry (Becton-Dickinson). An absence of Rhodamine 123 from cells indicated the loss of $\operatorname{MMP}\left(\Delta \Psi_{\mathrm{m}}\right)$ in HeLa cells.

Statistical analysis. The data were assessed using Instat software (GraphPad Prism4, San Diego, CA, USA). The Student's t-test or one-way analysis of variance (ANOVA) was used for parametric data. Statistical significance was defined as $\mathrm{p}<0.05$.

\section{Results}

Effects of GA on the growth of HeLa cells and HUVEC. The anti-growth effect of GA was examined in HeLa cells and HUVEC using MTT assays. In this study, HUVEC were used as normal control cells since GA shows no cytotoxicity against normal fibroblast and endothelial cells (13). After exposure to GA for $24 \mathrm{~h}$, HeLa cell growth was dose-dependently diminished with an $\mathrm{IC}_{50}$ of $\sim 80 \mu \mathrm{M}$ GA (Fig. 1A). At $72 \mathrm{~h}$, the growth of HeLa cells was completely inhibited at the concentrations of $>100 \mu \mathrm{M}$ GA (Fig. 1A). When the growth of HUVEC was assessed after treatment with GA, the dose-dependent reduction of cell growth was observed with an $\mathrm{IC}_{50}$ of $\sim 400 \mu \mathrm{M} \mathrm{GA}$ at $24 \mathrm{~h}$ (Fig. 1B).

Effects of GA on intracellular ROS levels in HeLa cells and HUVEC. To assess ROS levels in GA-treated HeLa cells and HUVEC, $\mathrm{H}_{2}$ DCFDA and DHE dyes were used for the detection of non-specific $\mathrm{ROS}$ and $\mathrm{O}_{2}{ }^{--}$levels, respectively. As shown in Fig. 2A and B, intracellular ROS (DCF) levels increased in HeLa cells treated with 50-400 $\mu \mathrm{M}$ GA from the early time phase of $30 \mathrm{~min}$ to $24 \mathrm{~h}$. ROS levels dose-dependently increased at $24 \mathrm{~h}$ (Fig. 2A and B). However, 50 or $100 \mu \mathrm{M}$ GA decreased ROS levels in HeLa cells at $72 \mathrm{~h}$ (Fig. 2B). In HUVEC, 100 or $200 \mu \mathrm{M}$ GA increased ROS levels at $24 \mathrm{~h}$ 

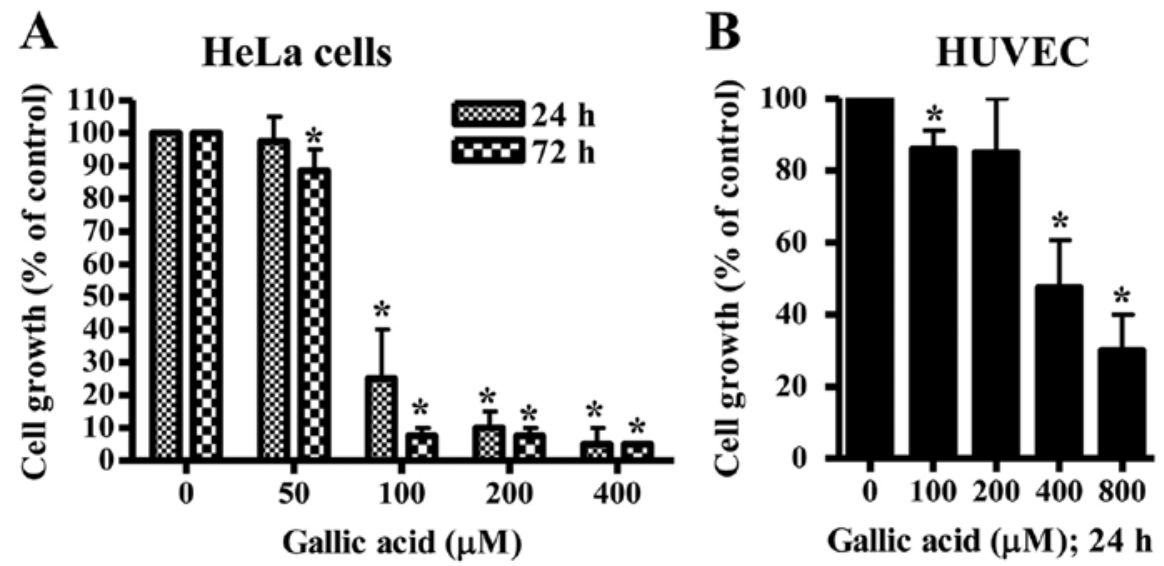

Gallic acid $(\mu \mathrm{M}) ; 24 \mathrm{~h}$

Figure 1. Effects of GA on the growth of HeLa cells and HUVEC in vitro. Exponentially-growing cells were treated with the indicated concentrations of GA for 24 or $72 \mathrm{~h}$. Cell growth inhibition was assessed by MTT assays. (A) HeLa cells at 24 or $72 \mathrm{~h}$. (B) HUVEC at $24 \mathrm{~h}$. "p $<0.05$ as compared with the GA-untreated control group.

A
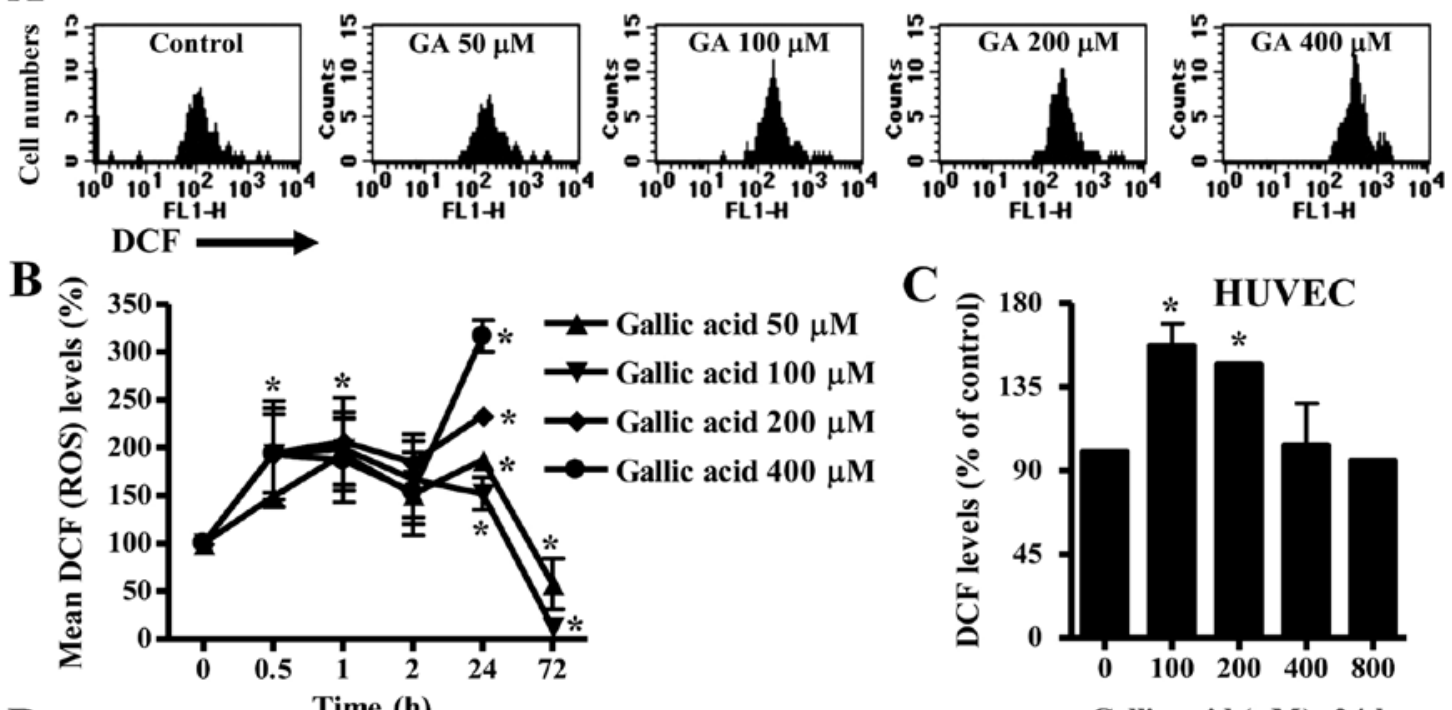

C

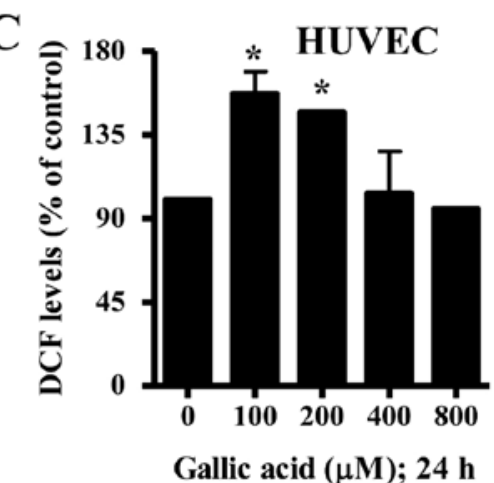

D

Time (h)

Gallic acid $(\mu \mathrm{M}) ; 24 \mathrm{~h}$
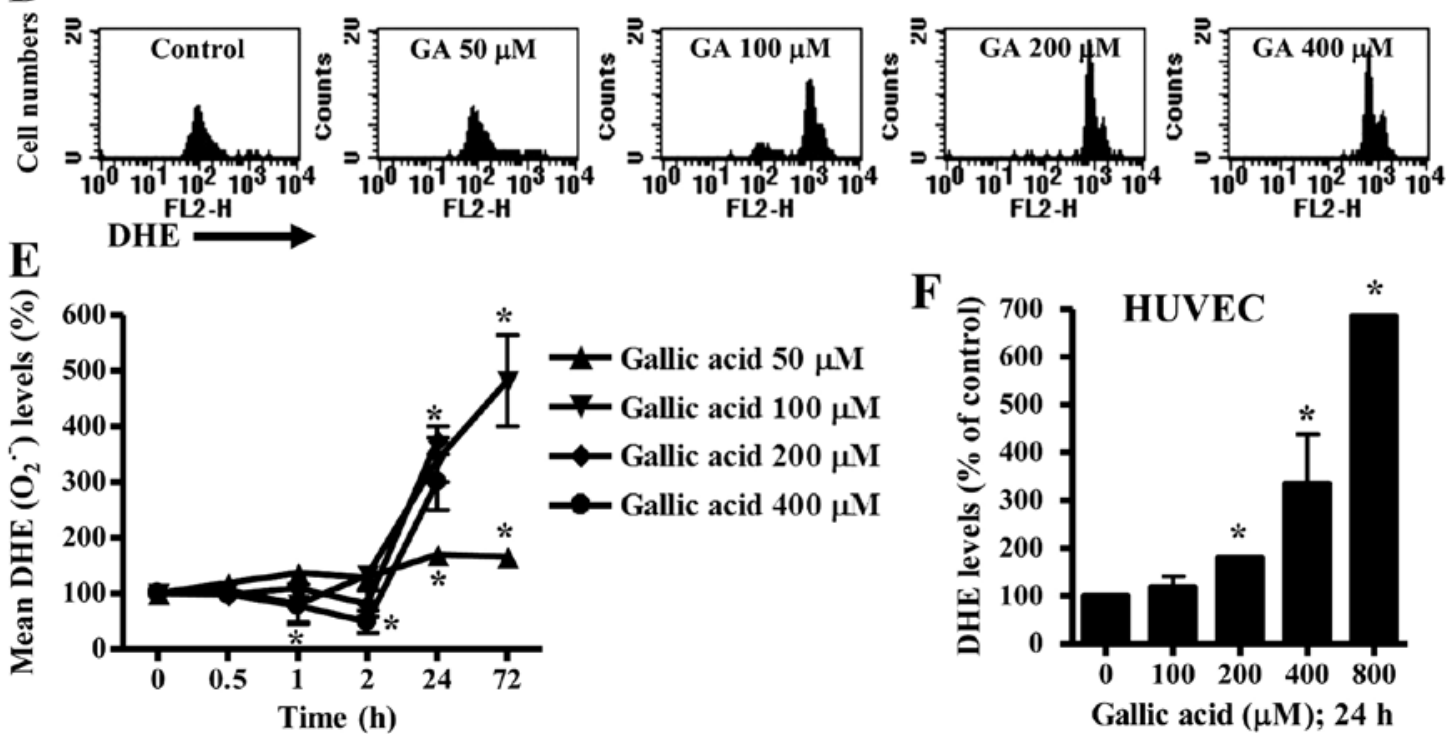

Figure 2. Effects of GA on ROS levels in HeLa cells and HUVEC. Exponentially-growing cells were treated with the indicated concentrations of GA for 0.5, 1 , 2, 24 or $72 \mathrm{~h}$. (A) Each histogram shows the levels of ROS (DCF) in GA-treated HeLa cells at $24 \mathrm{~h}$. (B and C) Graphs indicate DCF (ROS) levels (\%) in HeLa cells (B) and HUVEC (C) as compared with each control group cells. (D) Each histogram shows the levels of $\mathrm{O}_{2}^{-}$(DHE) in GA-treated HeLa cells at $24 \mathrm{~h}$. (E and F) Graphs indicate DHE $\left(\mathrm{O}_{2}^{\circ}\right)$ levels $(\%)$ in HeLa cells (E) and HUVEC (F) as compared with each control group cells. "p $<0.05$ as compared with the GA-untreated control group. 
$\mathbf{A}$

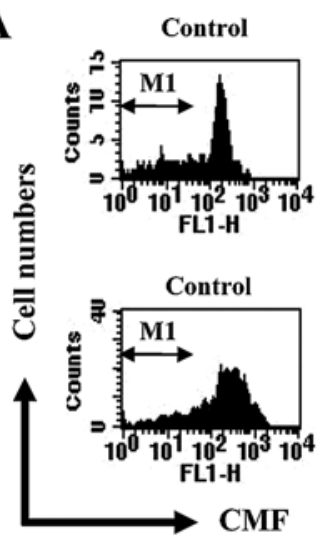

B

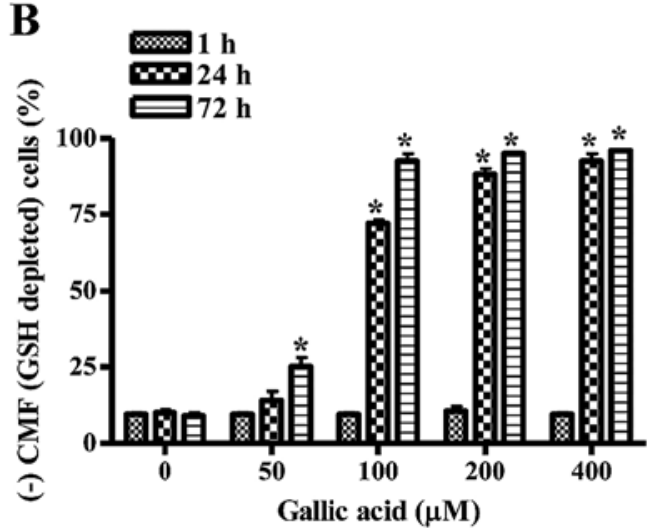

GA $50 \mu M$
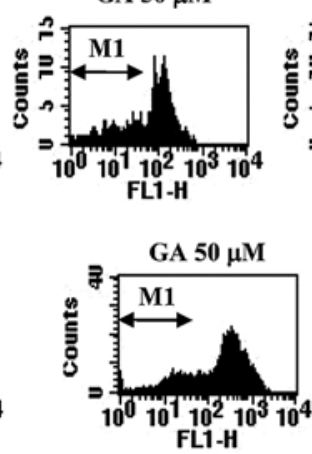

C

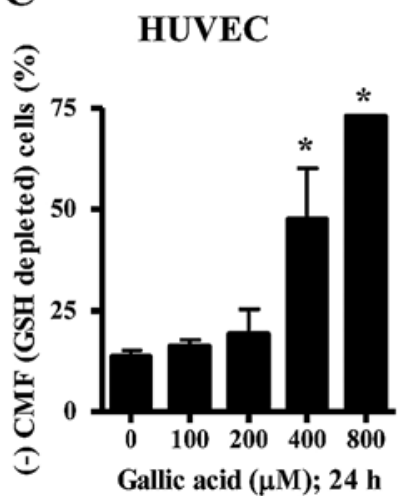

GA $200 \mu M$
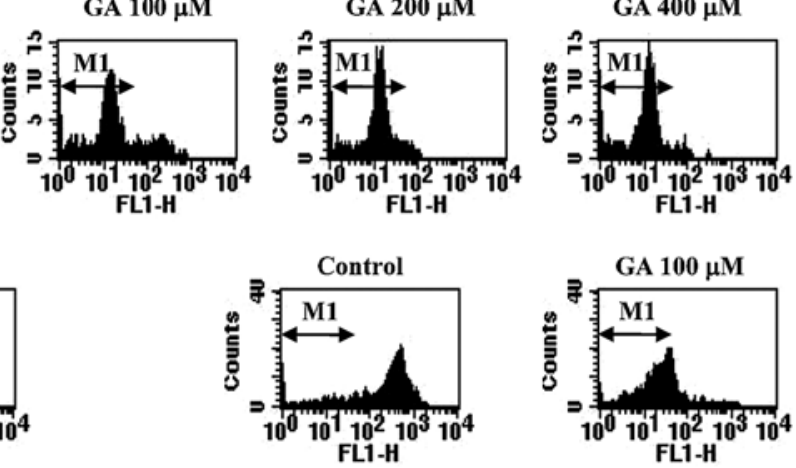

24

$72 \mathrm{~h}$

D $\quad$ Gallic acid $50 \mu \mathrm{M}$

$\rightarrow$ Gallic acid $100 \mu \mathrm{M}$

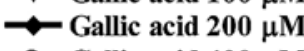

递 Gallic acid $400 \mu \mathrm{M}$

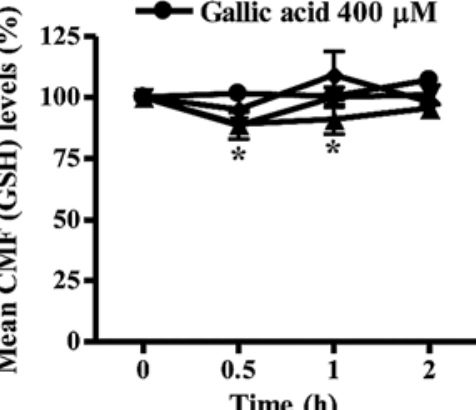

Figure 3. Effects of GA on GSH levels in HeLa cells and HUVEC. Exponentially-growing cells were treated with the indicated concentrations of GA for 0.5, 1, 2, 24 or 72 h. (A) Each histogram shows the levels of GSH (CMF) in HeLa cells at 24 or 72 h. M1 indicates the region of GSH depleted cells. (B) Graph shows the percents of (-) CMF (GSH-depleted; M1 region) cells in HeLa cells at 1, 24 or 72 h. (C) Graph shows the percents of (-) CMF (GSH-depleted) cells in HUVEC at $24 \mathrm{~h}$. (D) Graph indicates mean CMF (GSH) levels (\%) in HeLa cells at $0.1,1$ or $2 \mathrm{~h}$ as compared with each control group cell. *p<0.05 as compared with the GA-untreated control cell group.

whereas 400 and $800 \mu \mathrm{M}$ GA did not affect ROS levels at this time (Fig. 2C).

Intracellular $\mathrm{O}_{2}^{--}$levels slightly decreased in 200 or $400 \mu \mathrm{M}$ GA-treated HeLa cells from $1 \mathrm{~h}$ to $2 \mathrm{~h}$ whereas $\mathrm{O}_{2}{ }^{--}$levels were not significantly changed in 50 or $100 \mu \mathrm{M}$ GA-treated HeLa cells during these times (Fig. 2E). At 24 h, $\mathrm{O}_{2}{ }^{--}$levels dose-dependently increased in GA-treated HeLa cells (Fig. 2D and $\mathrm{E}$ ). The $\mathrm{O}_{2}^{--}$levels increased by 50 or $100 \mu \mathrm{M}$ GA lasted for $72 \mathrm{~h}$ (Fig. 2E). In addition, 200-800 $\mu \mathrm{M}$ GA increased $\mathrm{O}_{2}{ }^{-}$ levels in HUVEC at $24 \mathrm{~h}$ (Fig. 2F).

Effects of GA on intracellular GSH levels in HeLa cells and HUVEC. Next, changes in GSH levels were analyzed in GA-treated HeLa cells and HUVEC using CMF fluorescence dye. As shown in Fig. 3A and B, the numbers of GSH-depleted cells in GA-treated HeLa cells were dose-dependently increased at 24 or $72 \mathrm{~h}$. A dramatic increase in GSH-depleted cell number was observed in above $100 \mu \mathrm{M}$ GA-treated cells at 24 or $72 \mathrm{~h}$ (Fig. 3A and B). However, the tested doses of GA did not induce GSH depletion in HeLa cells at $1 \mathrm{~h}$ (Fig. 3B). In HUVEC, 100 or $200 \mu \mathrm{M}$ GA did not increase the numbers of GSH-depleted cells at $24 \mathrm{~h}$, but 400 or $800 \mu \mathrm{M}$ GA strongly increased the numbers (Fig. 3C). When GSH levels were measured in GA-treated HeLa cells at the early time phases of $0.5,1$ or $2 \mathrm{~h}, \mathrm{GSH}$ levels seemed to be decreased by GA during these times (Fig. 3D).
Effects of NAC and BSO on cell death and MMP $\left(\Delta \Psi_{m}\right)$ in GA-treated HeLa cells. Because GA inhibited the growth of HeLa cells, this study investigated the effects of NAC or BSO on the growth and death of 50 or $100 \mu \mathrm{M}$ GA-treated HeLa cells at $24 \mathrm{~h}$. Treatment with NAC significantly decreased the growth of $50 \mu \mathrm{M}$ GA-treated HeLa cells and BSO slightly decreased the growth (Fig. 4A). In addition, $50 \mu \mathrm{M}$ GA slightly increased the numbers of Annexin V-FITC-positive cells in HeLa cells, but $100 \mu \mathrm{M}$ GA strongly increased Annexin V-FITC-positive cell numbers (Fig. 4B). NAC, but not BSO, increased the numbers of Annexin V-FITC-positive cells in $50 \mu \mathrm{M}$ GA-treated HeLa cells (Fig. 4B). Furthermore, mitochondrial membrane potential (MMP; $\Delta \Psi_{\mathrm{m}}$ ) levels in GA-treated HeLa cells were analyzed in the presence or absence of NAC and BSO at $24 \mathrm{~h}$. Similar to the Annexin V staining results, $100 \mu \mathrm{M}$, but not $50 \mathrm{GA} \mu \mathrm{M}$, markedly triggered the loss of MMP $\left(\Delta \Psi_{\mathrm{m}}\right)$ in HeLa cells (Fig. 4C). Both NAC and BSO significantly increased the loss of MMP $\left(\Delta \Psi_{\mathrm{m}}\right)$ in $50 \mu \mathrm{M}$ GA-treated HeLa cells (Fig. 4C). NAC or BSO alone did not trigger the loss of MMP $\left(\Delta \Psi_{\mathrm{m}}\right)$ in HeLa control cells (data not shown).

Effects of NAC and BSO on ROS and GSH levels in GA-treated HeLa cells. It was assessed whether ROS and GSH levels in GA-treated HeLa cells were changed or not by NAC or BSO at $24 \mathrm{~h}$. As shown in Fig. 5A, ROS (DCF) level in $50 \mu \mathrm{M}$ 
A

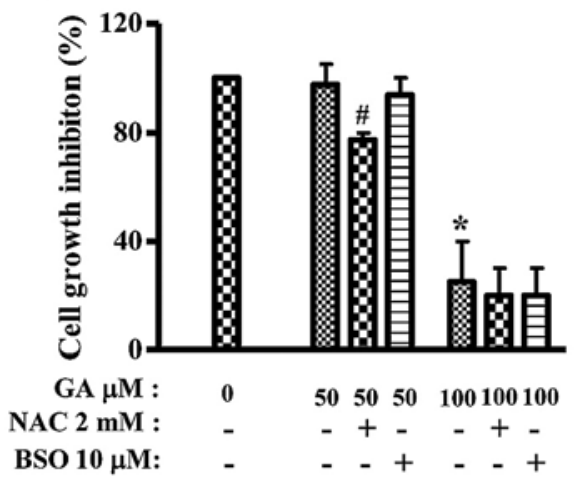

B

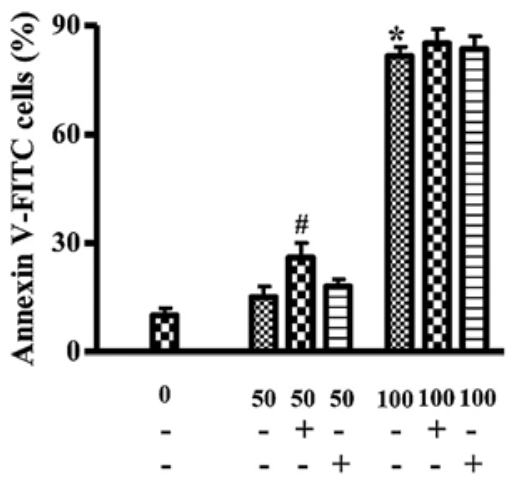

C

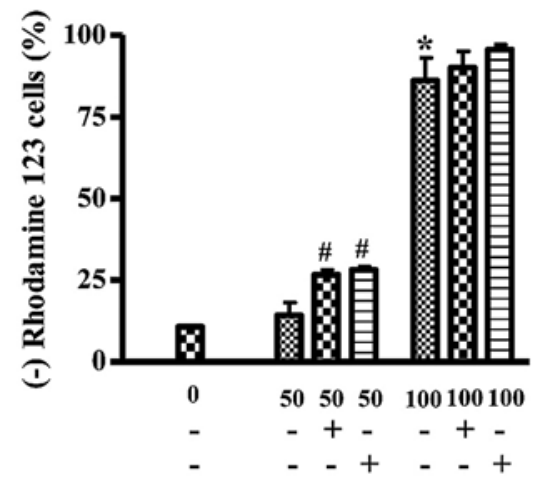

Figure 4. Effects of NAC and BSO on cell growth, death and MMP $\left(\Delta \Psi_{\mathrm{m}}\right)$ in GA-treated HeLa cells. Exponentially-growing HeLa cells were treated with 50 or $100 \mu \mathrm{M}$ GA for $24 \mathrm{~h}$ following $1 \mathrm{~h}$ pre-incubation of $2 \mathrm{mM}$ NAC or $10 \mu \mathrm{M}$ BSO. (A) Graph shows the growth of HeLa cells, as assessed by an MTT assay. (B and C) Graphs show the percents of Annexin V-FITC staining cells (B) and Rhodamine 123-negative [MMP ( $\left.\Delta \Psi_{\mathrm{m}}\right)$ loss] cells $(\mathrm{C})$, as measured with a FACStar flow cytometer. ${ }^{*} \mathrm{p}<0.05$ as compared with the control group. ${ }^{\#} \mathrm{p}<0.05$ as compared with cells treated with $50 \mu \mathrm{M}$ GA only.

A

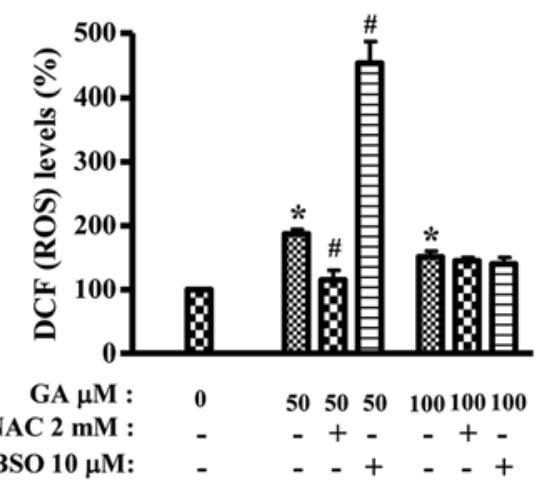

B

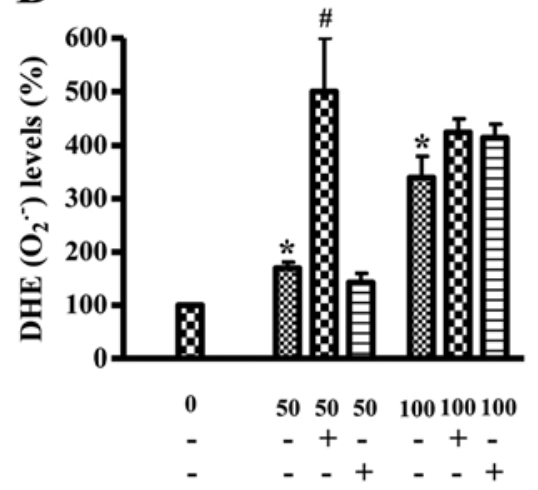

C

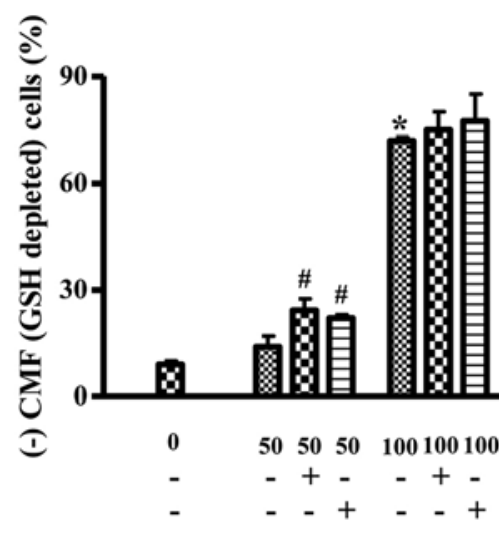

Figure 5. Effects of NAC and BSO on ROS and GSH levels in GA-treated HeLa cells. Exponentially-growing HeLa cells were treated with 50 or $100 \mu \mathrm{M}$ GA for $24 \mathrm{~h}$ following $1 \mathrm{~h}$ pre-incubation of $2 \mathrm{mM}$ NAC or $10 \mu \mathrm{M}$ BSO. (A and B) Graphs indicate DCF (ROS) and DHE (O) $\left.{ }_{2}^{\circ}\right)$ levels (\%) as compared with control

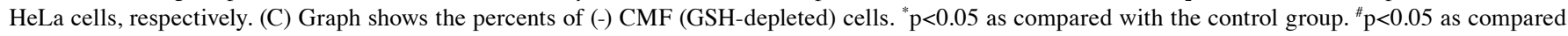
with cells treated with $50 \mu \mathrm{M}$ GA only.

GA-treated HeLa cells was significantly decreased by NAC whereas BSO strongly increased ROS (DCF) level in these cells. NAC and BSO did not alter ROS (DCF) level in $100 \mu \mathrm{M}$ GA-treated HeLa cells (Fig. 5A). In contrast, NAC intensified $\mathrm{O}_{2}^{--}$level in $50 \mu \mathrm{M}$ GA-treated HeLa cells and slightly increased $\mathrm{O}_{2}{ }^{--}$level in $100 \mu \mathrm{M} \mathrm{GA}$-treated HeLa cells (Fig. 5B). BSO slightly decreased $\mathrm{O}_{2}{ }^{-}$level in $50 \mu \mathrm{M}$ GA-treated HeLa cells but it increased $\mathrm{O}_{2}{ }^{\circ-}$ level in $100 \mu \mathrm{M}$ GA-treated HeLa cells (Fig. 5B). In relation to GSH level, NAC and BSO significantly increased the numbers of GSH-depleted cells in $50 \mu \mathrm{M}$ GA-treated HeLa cells at $24 \mathrm{~h}$ (Fig. 5C). Both agents also mildly increased GSH-depleted cell numbers in $100 \mu \mathrm{M}$ GA-treated HeLa cells (Fig. 5C). NAC or BSO alone did not significantly change $\mathrm{GSH}$ and $\mathrm{ROS}$ levels including $\mathrm{O}_{2}{ }^{\circ}$.

\section{Discussion}

This study focused on evaluating the effects of GA on the growth and death of HeLa cells in relation to ROS and GSH levels. This study also demonstrated that the susceptibility of HeLa cells to GA was higher than that of HUVEC. This result was similar to the report that GA shows the lower cytotoxicity against normal fibroblast and endothelial cells (13). GA is reported to induce apoptosis in prostate cancer cells via mitochondrial dysfunction (28). Likewise, GA seemed to induce apoptosis in HeLa cells and it triggered the loss of $\operatorname{MMP}\left(\Delta \Psi_{\mathrm{m}}\right)$.

GA has been reported to have both pro-oxidant and/or antioxidant properties $(16,17)$. Increasing evidence suggests that apoptosis induced by GA is associated with oxidative stresses derived from $\operatorname{ROS}(8,12,28)$. According to our results, the intracellular ROS (DCF) levels increased in GA-treated HeLa cells from the early time phases. ROS levels also dose-dependently increased at $24 \mathrm{~h}$. Interestingly, 50 or $100 \mu \mathrm{M} \mathrm{GA}$ showing an apoptotic effect at $72 \mathrm{~h}$ decreased ROS levels. In contrast, GA slightly decreased $\mathrm{O}_{2}{ }^{-}$levels at the early time phases and it increased $\mathrm{O}_{2}{ }^{--}$levels at 24 or $72 \mathrm{~h}$. In relation to HUVEC, 100 or $200 \mu \mathrm{M}$ GA increased ROS levels at $24 \mathrm{~h}$ whereas 400 and $800 \mu \mathrm{M}$ GA showed a significant growth inhibition and cell death did not increase ROS levels. Treatment with the $>200 \mu \mathrm{M}$ GA increased $\mathrm{O}_{2}{ }^{-}$levels in HUVEC at $24 \mathrm{~h}$. In addition, GA increases ROS levels including $\mathrm{O}_{2}{ }^{--}$at $24 \mathrm{~h}$ in lung 
cancer and normal cells $(7,29)$. These results suggest that GA can individually affect different ROS levels depending on the incubation times and doses, and cell types.

NAC showing the reduction of ROS (DCF) level in $50 \mu \mathrm{M}$ GA-treated HeLa cells significantly enhanced growth inhibition and cell death in these cells. In addition, NAC strongly increased $\mathrm{O}_{2}{ }^{-}$level in GA-treated HeLa cells. Therefore, although NAC decreased ROS (DCF) level in GA-treated HeLa cells, NAC seemed to act as a pro-oxidant because of increasing $\mathrm{O}_{2}^{--}$level and cell death in these cells. Similarly, NAC intensified the growth inhibition and death in GA-treated lung cancer, which were accompanied by a decrease in ROS (DCF) level and an increase in $\mathrm{O}_{2}{ }^{-}$level (7). BSO showing a strong increased effect of ROS (DCF) on GA-treated HeLa cells did not affect cell growth and death but it increased the loss of MMP $\left(\Delta \Psi_{m}\right)$ in these cells. Taken together, these results suggest that changes in ROS levels by GA are not tightly but at least partially related to HeLa cell death. The exact role of ROS, especially $\mathrm{O}_{2}{ }^{-}$needs to be defined further in GA-induced HeLa cell death.

It has been reported that the intracellular GSH content has a decisive effect on anticancer drug-induced apoptosis, indicating that apoptotic effects are inversely comparative to GSH content $(30,31)$. The intracellular GSH content also is involved in GA-induced cell death (7,29). Likewise, GA dose-dependently increased the numbers of GSH-depleted cells in HeLa cells and HUVEC. The decreased GSH levels in GA-treated HeLa cells at the early times probably resulted from ROS (DCF) level increased by GA. In addition, NAC showing the enhancement of cell death in GA-treated HeLa cells significantly increased the numbers of GSH-depleted cells. Similarly, NAC enhances GSH depletion in GA-treated lung cancer and normal cells $(7,29)$. Although it is known that NAC as a GSH precursor contains a thiol group, NAC used in this study did not seem to be a GSH precursor in GA-treated HeLa cells. However, NAC significantly prevented GSH depletion in propyl gallate-treated HeLa cells (32). Therefore, it is considered that NAC can be a GSH precursor or not depending on co-incubated agents. BSO significantly increased the numbers of GSH-depleted cells in GA-treated HeLa cells. BSO also augmented GSH depletion and cell death in GA-treated lung cancer and normal cells $(7,29)$. However, BSO enhanced the loss of $\operatorname{MMP}\left(\Delta \Psi_{\mathrm{m}}\right)$ in GA-treated HeLa cells without a significant increase in cell death, implying that GSH depletion in these cells was correlated with MMP $\left(\Delta \Psi_{\mathrm{m}}\right)$ loss rather than cell death. Taken together, these results suggest that the intracellular GSH content seem to have a vital role on GA-induced cell death but changes in GSH levels are not sufficient enough to precisely predict cell death.

In conclusion, GA significantly inhibited the growth of HeLa cells. Changes in ROS levels, especially $\mathrm{O}_{2}{ }^{-}$affected GA-induced HeLa cell death. GA-induced HeLa cell death correlated with GSH depletion.

\section{Acknowledgements}

This study was supported by a grant from the National Research Foundation of Korea (NRF) funded by the Korean government (MSIP; nos. 2008-0062279 and 2016R1A2B4007773).

\section{References}

1. Chu YF, Sun J, Wu X and Liu RH: Antioxidant and antiproliferative activities of common vegetables. J Agric Food Chem 50: 6910-6916, 2002.

2. Shahrzad S, Aoyagi K, Winter A, Koyama A and Bitsch I: Pharmacokinetics of gallic acid and its relative bioavailability from tea in healthy humans. J Nutr 131: 1207-1210, 2001.

3. Kang MS, Oh JS, Kang IC, Hong SJ and Choi CH: Inhibitory effect of methyl gallate and gallic acid on oral bacteria. J Microbiol 46: 744-750, 2008.

4. Kratz JM, Andrighetti-Fröhner CR, Leal PC, Nunes RJ, Yunes RA, Trybala E, Bergström T, Barardi CR and Simões CM: Evaluation of anti-HSV-2 activity of gallic acid and pentyl gallate. Biol Pharm Bull 31: 903-907, 2008.

5. Kim SH, Jun CD, Suk K, Choi BJ, Lim H, Park S, Lee SH, Shin HY, Kim DK and Shin TY: Gallic acid inhibits histamine release and pro-inflammatory cytokine production in mast cells. Toxicol Sci 91: 123-131, 2006.

6. You BR, Kim SZ, Kim SH and Park WH: Gallic acid-induced lung cancer cell death is accompanied by ROS increase and glutathione depletion. Mol Cell Biochem 357: 295-303, 2011.

7. You BR and Park WH: Gallic acid-induced lung cancer cell death is related to glutathione depletion as well as reactive oxygen species increase. Toxicol In Vitro 24: 1356-1362, 2010.

8. Inoue $\mathrm{M}$, Sakaguchi N, Isuzugawa $\mathrm{K}$, Tani $\mathrm{H}$ and Ogihara $\mathrm{Y}$ : Role of reactive oxygen species in gallic acid-induced apoptosis. Biol Pharm Bull 23: 1153-1157, 2000.

9. Agarwal C, Tyagi A and Agarwal R: Gallic acid causes inactivating phosphorylation of cdc25A/cdc25C-cdc2 via ATM-Chk2 activation, leading to cell cycle arrest, and induces apoptosis in human prostate carcinoma DU145 cells. Mol Cancer Ther 5: 3294-3302, 2006.

10. Faried A, Kurnia D, Faried LS, Usman N, Miyazaki T, Kato H and Kuwano H: Anticancer effects of gallic acid isolated from Indonesian herbal medicine, Phaleria macrocarpa (Scheff.) Boerl, on human cancer cell lines. Int J Oncol 30: 605-613, 2007.

11. You BR, Moon HJ, Han YH and Park WH: Gallic acid inhibits the growth of HeLa cervical cancer cells via apoptosis and/or necrosis. Food Chem Toxicol 48: 1334-1340, 2010.

12. Serrano A, Palacios C, Roy G, Cespón C, Villar ML, Nocito M and González-Porqué P: Derivatives of gallic acid induce apoptosis in tumoral cell lines and inhibit lymphocyte proliferation. Arch Biochem Biophys 350: 49-54, 1998.

13. Inoue M, Suzuki R, Sakaguchi N, Li Z, Takeda T, Ogihara Y, Jiang BY and Chen Y: Selective induction of cell death in cancer cells by gallic acid. Biol Pharm Bull 18: 1526-1530, 1995.

14. Sohi KK, Mittal N, Hundal MK and Khanduja KL: Gallic acid, an antioxidant, exhibits antiapoptotic potential in normal human lymphocytes: A Bcl-2 independent mechanism. J Nutr Sci Vitaminol (Tokyo) 49: 221-227, 2003.

15. Giftson JS, Jayanthi S and Nalini N: Chemopreventive efficacy of gallic acid, an antioxidant and anticarcinogenic polyphenol, against 1,2-dimethyl hydrazine induced rat colon carcinogenesis. Invest New Drugs 28: 251-259, 2010.

16. Strlic M, Radovic T, Kolar J and Pihlar B: Anti- and prooxidative properties of gallic acid in fenton-type systems. J Agric Food Chem 50: 6313-6317, 2002.

17. Sakagami H and Satoh K: Prooxidant action of two antioxidants: Ascorbic acid and gallic acid. Anticancer Res 17A: 221-224, 1997.

18. Gonzalez C, Sanz-Alfayate G, Agapito MT, Gomez-Niño A, Rocher A and Obeso A: Significance of ROS in oxygen sensing in cell systems with sensitivity to physiological hypoxia. Respir Physiol Neurobiol 132: 17-41, 2002.

19. Baran CP, Zeigler MM, Tridandapani S and Marsh CB: The role of ROS and RNS in regulating life and death of blood monocytes. Curr Pharm Des 10: 855-866, 2004.

20. Zorov DB, Juhaszova $M$ and Sollott SJ: Mitochondrial ROS-induced ROS release: An update and review. Biochim Biophys Acta 1757: 509-517, 2006.

21. Zelko IN, Mariani TJ and Folz RJ: Superoxide dismutase multigene family: A comparison of the CuZn-SOD (SOD1), Mn-SOD (SOD2), and EC-SOD (SOD3) gene structures, evolution, and expression. Free Radic Biol Med 33: 337-349, 2002.

22. Wilcox CS: Reactive oxygen species: Roles in blood pressure and kidney function. Curr Hypertens Rep 4: 160-166, 2002.

23. Han YH and Park WH: The effects of $\mathrm{N}$-acetyl cysteine, buthionine sulfoximine, diethyldithiocarbamate or 3-amino-1,2,4-triazole on antimycin A-treated Calu-6 lung cells in relation to cell growth, reactive oxygen species and glutathione. Oncol Rep 22: 385-391, 2009. 
24. Han YH, Moon HJ, You BR, Kim SZ, Kim SH and Park WH: Effects of carbonyl cyanide p-(trifluoromethoxy) phenylhydrazone on the growth inhibition in human pulmonary adenocarcinoma Calu-6 cells. Toxicology 265: 101-107, 2009.

25. Han YH, Kim SH, Kim SZ and Park WH: Caspase inhibitor decreases apoptosis in pyrogallol-treated lung cancer Calu- 6 cells via the prevention of GSH depletion. Int J Oncol 33: 1099-1105, 2008.

26. Han YH, Kim SZ, Kim SH and Park WH: Apoptosis in pyrogallol-treated Calu- 6 cells is correlated with the changes of intracellular GSH levels rather than ROS levels. Lung Cancer 59: 301-314, 2008.

27. You BR, Kim SH and Park WH: Reactive oxygen species, glutathione, and thioredoxin influence suberoyl bishydroxamic acid-induced apoptosis in A549 lung cancer cells. Tumour Biol 36: 3429-3439, 2015.
28. Chen HM, Wu YC, Chia YC, Chang FR, Hsu HK, Hsieh YC, Chen CC and Yuan SS: Gallic acid, a major component of Toona sinensis leaf extracts, contains a ROS-mediated anti-cancer activity in human prostate cancer cells. Cancer Lett 286: 161-171, 2009.

29. You BR and Park WH: Enhancement of gallic acid-induced human pulmonary fibroblast cell death by $\mathrm{N}$-acetyl cysteine and L-buthionine sulfoximine. Hum Exp Toxicol 30: 992-999, 2011.

30. Estrela JM, Ortega A and Obrador E: Glutathione in cancer biology and therapy. Crit Rev Clin Lab Sci 43: 143-181, 2006.

31. Han YH, Kim SZ, Kim SH and Park WH: Intracellular GSH level is a factor in As4.1 juxtaglomerular cell death by arsenic trioxide. J Cell Biochem 104: 995-1009, 2008.

32. Han YH and Park WH: Propyl gallate inhibits the growth of HeLa cells via regulating intracellular GSH level. Food Chem Toxicol 47: 2531-2538, 2009. 